\title{
EFFECT OF ADDITION OF ACTIVATED CHARCOAL TO DIFFERENT FORMULATIONS OF CALCIUM HYDROXIDE ON DENTIN MICROHARDNESS OF ENDODONTICALLY TREATED TEETH. (AN IN-VITRO STUDY)
}

\author{
Medhat Taha Elfaramawy*
}

\begin{abstract}
This study evaluated the effect of addition of the activated charcoal to different formulations of calcium hydroxide on dentin microhardness of endodontically treated teeth. Ninety one freshly human extracted single rooted teeth were selected. The samples were cleaned and shaped and classified according to the type of the dressing into five groups; Group 1; (21 samples) dressed with calcium hydroxide paste with Iodoform (Metapex) (META, Chungcheongbuk-do, Korea), Group 2; (21 samples) dressed with conventional calcium hydroxide with saline (GAMA dental lab, Cairo, Egypt). Group 3; (21 samples) dressed with calcium hydroxide paste with Iodoform mixed with activated charcoal (Eucarbon Sedico, Cairo, Egypt) and Group 4; (21 samples) dressed with conventional calcium hydroxide and activated charcoal with saline and Group 5; Control group (undressed). The samples were further classified according to the observation time into: Subgroup A; (7 samples) after two weeks. Subgroup B; (7 samples) after one month and Subgroup C; (7 samples) after two months. The microhardness measurements were performed using a Vickers Microhardness Tester (Model HVS-50, Laizhou Huayin Testing Instrument Co., Ltd. China). The results showed that there was a continuous decrease in the values of dentin microhardness by time however the samples with activated charcoal showed higher mirohardness over the tested periods. It was concluded that the addition of activated charcoal to the calcium hydroxide compounds can decrease the softening effect of different formulations of calcium hydroxide on the root canal dentin.
\end{abstract}

KEYWORDS: Activated Charcoal, Calcium Hydroxide, Microhardness.

\section{INTRODUCTION}

Fava and saunders ${ }^{(3)}$ stated that calcium hydroxide compounds gain their action through the chemical dissociation into calcium ions and hydroxyl ions. This mode of action has a strong antibacterial effect ${ }^{(1,8)}$ and effective antiinflammatory action. This advantage has on the other hand strong disadvantage through the effect of calcium hydroxide on the mechanical properties of root canal dentine. One of these mechanical

\footnotetext{
* Associate Professor, Endodontic Department, Faculty of Dentistry, Ainshams University.
} 
properties is dentin microhardness which is affected directly by the use of calcium hydroxide as an intracanal medication ${ }^{(10,11)}$. Different attempts were made to decrease the weakening effect of calcium hydroxide on the mechanical properties of endodontically treated teeth without hindering their anti-microbial properties.

\section{MATERIALS AND METHODS}

\section{1) Samples selection}

Ninety one freshly human extracted single rooted teeth were inspected under surgical microscope to exclude any cracks or fracture lines. Teeth were decoronated at cement-enamel junction using diamond bur in high speed with air/water coolant. Teeth were stored in saline till used.

\section{2) Root canal instrumentation}

Biomechanical preparation of samples was done in step back manner reaching file \#50 as a master apical file and last file for flaring was \#70. Irrigation of the samples was carried out using sodium hypochlorite $2.5 \%$. and patency of the samples was ensured using file \#10. After dressing of the samples according to its classification the coronal portion was sealed with glass ionomer filling. The samples of the control group was tested without dressing after biomechanical preperation.

\section{3) Samples Classification}

Samples were classified according to the type of the dressing into five groups; Group 1; (21 samples) dressed with calcium hydroxide paste with Iodoform (Metapex) (META, Chungcheongbuk-do, Korea ), Group 2; (21 samples) dressed with conventional calcium hydroxide with saline(GAMA dental lab, Cairo, Egypt ). Group 3; (21 samples) dressed with calcium hydroxide paste with Iodoform mixed with activated charcoal ( Eucarbon Sedico, Cairo, Egypt) with ratio of 1-1 by weight and Group 4; (21 samples) dressed with conventional calcium hydroxide and activated charcoal with ratio of 1-1 by weight and Group 5; Control group (undressed). The samples were further classified according to the observation time into: Subgroup A; (7 samples) after two weeks. Subgroup B;(7 samples) after one month and Subgroup C; (7 samples) after two months.

\section{4) Samples preparation}

Mounting of the samples in self-cured acrylic resin using plastic syringes $(10 \mathrm{~cm} 3) .7-8 \mathrm{~mm}$ of the coronal portion of the mounted samples were cut using diamond bur with air/water spray to expose the middle one third of the root canal dentin which then was finished and polished using sand paper discs.

\section{5) Method of evaluation}

Vickers microhardness Tester (Model HVS-50, Laizhou Huayin Testing Instrument Co., Ltd. China) was used. The microhardness measurements were taken at a point mid-way between the outer surface and the canal wall. Each measurement was carried out by using a $200-\mathrm{g}$ load for 10 seconds oriented perpendiculary to the root surface. The diagonal lengths of indentations were measured by built in scaled microscope.

\section{6) Statistical analysis}

IBM SPSS V23 (IBM, USA) statistical analysis software was used for Data analysis. ANOVA and Kruskal-Wallis tests were used to compare data in each group. The level of significance was set at 0.05 .

\section{RESULT}

\section{Group 1: (Metapex).}

The average value of dentin microhardness decreased by time as it was $48 \pm 1.5$ after two weeks, $45 \pm 2$ after one month and $40 \pm 1.9$ after two months.

The difference was significant between the value of dentin microhardness after two months and the value for two weeks and one month. 
Table (1) Dentin microhardness (average and standard deviation) of different groups. (Kgf/mm²).

\begin{tabular}{|c|c|c|c|c|c|c|}
\hline Group & Metapex & Conv. $\mathrm{Ca}(\mathrm{OH})_{2}$ & $\begin{array}{l}\text { Metapex } \\
\text { +A.Charc. }\end{array}$ & $\begin{array}{c}\text { Conv. } \mathrm{Ca}(\mathrm{OH})_{2}+\mathrm{A} . \\
\text { Charc. }\end{array}$ & Control & P-value \\
\hline 2 weeks & $48 \pm 1.5 * \mathrm{a}$ & $48.8 \pm 1.1^{* \mathrm{a}}$ & $50 \pm 1.4^{* a}$ & $49.5 \pm 1.4 * \mathrm{a}$ & \multirow[t]{3}{*}{$52 \pm 1.2$} & $<0.0001$ \\
\hline One month & $45 \pm 2 * a$ & $46.7 \pm 1.2 * a$ & $48.7 \pm 2 * a$ & $48.8 \pm 2.3 * \mathrm{a}$ & & $<0.0001$ \\
\hline Two months & $40 \pm 1.9^{* * a}$ & $41.2 \pm 2 * * a$ & $47 \pm 1.6 * \mathrm{~b}$ & $47.9 \pm 2 * b$ & & $<0.0001$ \\
\hline
\end{tabular}

* For column and letters for raws.

\section{Group 2: $\mathrm{Conv} \mathrm{Ca}(\mathrm{OH})_{2}$}

There was a significant decrease in the dentin microhardness reaching $41.2 \pm 2$ after two months

\section{Group 3: (Metapex + Activated charcoal).}

There was a decrease in the average value of dentin microhardness with time but the difference was not statistically significant.

\section{Group 4: (Conv. $\left(\mathrm{Ca}(\mathrm{OH})_{2}+\right.$ Activated charcoal $)$}

The decrease in the average values of dentin microhardness was not statistically significant by time.

For all tested groups there was no statistically significant difference in the average values of dentin microhardness regarding two weeks and one month observation periods. However the difference was significant in the values recorded after two months observation periods with the groups with added activated charcoal showing higher microhardness values.

\section{DISCUSSION}

Calcium hydroxide is considered the most public material used for intra canal medication because of its strong antibacterial action ${ }^{(1,4)}$ and its potent anti-inflammatory behavior ${ }^{(2,7,9)}$. This advantageous action is gained through its ionic dissociation into calcium and hydroxyl ions ${ }^{(3)}$. However
$P \leq 0.05$ is considered significant.

this action is non-selective and so can affect the root canal dentin through hindering its mechanical properties ${ }^{(10,11)}$. Many attempts were made to overcome this disadvantageous reaction of calcium hydroxide through changing the mixing vehicle or adding certain compounds and even changing the particle size by using nano-technology ${ }^{(6)}$. Measurements of dentin microhardness is done to test the strength and abrasion resistance of root canal dentin (5). The results showed that there was a continuous decrease in the dentin microhardness by time with the use of calcium hydroxide compounds which may be related to continuous transportation of calcium ions from root canal dentin to inside the canal by concentration gradient ${ }^{(10,11)}$. However with the addition of the activated charcoal to the tested calcium hydroxide compounds the decrease in the dentine microhardness was not statistically significant which may be related to the adsorption effect of activated charcoal that increase the calcium ion concentration inside the calcium hydroxide and hence decreases the calcium transportation from the root canal dentin.

\section{CONCLUSION}

It was concluded that the addition of activated charcoal to the calcium hydroxide compounds can decrease the softening effect of different formulations of calcium hydroxide on the root canal dentin. 


\section{REFERENCES}

1. Baik J.E., Kum K.Y., Yun C.H. et al. 2008: Calcium Hydroxide Inactivates Lipoteichoic Acid from Enterococcus faecalis. J. Endod., 34 , 1355-59.

2. Broon N.J., Bortoluzzi E.A. and Bramante C.M.2007. Repair of large periapical radiolucent lesions of endodontic origin without surgical treatment. Aust. Endod. J. $33,36-41$.

3. Fava L.R.G. and W. P. 1999. Saunders W.P.: Calcium hydroxide pastes: classification and clinical indications. Int. Endod. J., 32, 257-282.

4. Khan A.A., Sun X. and Hargreaves K.M. 2008. Effect of calcium hydroxide on proinflammatory cytokines and neuropeptides. J. Endod., 34, 1360-63.

5. Lewinstein I. and Grajower R. 1981. Root dentin hardness of endodontically treated teeth. J., Endod., 7, 421-422.

6. Mandana N., Eftekhar L. Gholami F., Atai M. and Dianat O. 2019. The effect of calcium hydroxide and nano calcium hydroxide on microhardness and superficial chemical structure of root canal dentin an X-vivo study. J. Endod., $45,1148-1154$

7. Saatchi M. 2007: Healing of large periapical lesion: A nonsurgical endodontic treatment approach. Aust. Endod. J., $33,136-140$

8. Segura J.J., Llamas R., Manzanaris A.J., Planas A.J. 1997, Guerrero J.M. and Calvo J.R.: Calcium hydroxide inhibits substrate adhesion capacity of macrophages. J. Endod., $32,444-447$.

9. Soares J.A., Carvalho F.B., Pappen F.G etal. 2007. Conservative treatment of patients with periapical lesions associated with extraoral sinus tracts. Aust. Endod. J., 33, 131-135.

10. White J.D., Lacefield W.R., Chavers L.S. and Eleazer P.D 2002: The effect of three commonly used endodontic materials on the strength and hardness of root dentin. J. Endod., 28, 828-830.

11. Yoldas O., Dogan C. and Seydaoglu G. 2004. The effect of two different calcium hydroxide combinations on root dentine microhardness. Int. Endod. J. 37, 828-831. 